\title{
Isolation and characterization of microsatellite markers and analysis of genetic variability in Curculigo latifolia Dryand
}

\author{
Nahid Babaei • Nur Ashikin Psyquay Abdullah • \\ Ghizan Saleh • Thohirah Lee Abdullah
}

Received: 15 March 2012/ Accepted: 11 June 2012/Published online: 30 June 2012

(C) The Author(s) 2012. This article is published with open access at Springerlink.com

\begin{abstract}
Curculin, a sweet protein found in Curculigo latifolia fruit has great potential for the pharmaceutical industry. This protein interestingly has been found to have both sweet taste and taste-modifying capacities comparable with other natural sweeteners. According to our knowledge this is the first reported case on the isolation of microsatellite loci in this genus. Hence, the current development of microsatellite markers for $C$. latifolia will facilitate future population genetic studies and breeding programs for this valuable plant. In this study 11 microsatellite markers were developed using $3^{\prime}$ and $5^{\prime}$ ISSR markers. The primers were tested on 27 accessions from all states of Peninsular Malaysia. The number of alleles per locus ranged from three to seven, with allele size ranging from 141 to $306 \mathrm{bp}$. The observed and expected heterozygosity ranged between $0.00-0.65$ and $0.38-0.79$, respectively. The polymorphic information content ranged from 0.35 to 0.74 and the Shannon's information index ranged from 0.82 to 1.57 . These developed polymorphic microsatellites were used for constructing a dendrogram by unweighted pair group method with arithmetic mean cluster analysis using the Dice's similarity coefficient. Accessions
\end{abstract}

Electronic supplementary material The online version of this article (doi:10.1007/s11033-012-1853-z) contains supplementary material, which is available to authorized users.

N. Babaei · N. A. P. Abdullah $(\bowtie) \cdot$ G. Saleh · T. L. Abdullah Department of Crop Science, Faculty of Agriculture, Universiti Putra Malaysia, 43400 Serdang, Selangor, Malaysia

e-mail: nurashikin@putra.upm.edu.my

N. Babaei

e-mail: nahid.babaei@yahoo.com

G. Saleh

e-mail: ghizan@agri.upm.edu.my

T. L. Abdullah

e-mail: thohirah@agri.upm.edu.my association according to their geographical origin was observed. Based on characteristics of isolated microsatellites for $C$. latifolia accessions all genotype can be distinguished using these 11 microsatellite markers. These polymorphic markers could also be applied to studies on uniformity determination and somaclonal variation of tissue culture plantlets, varieties identification, genetic diversity, analysis of phylogenetic relationship, genetic linkage maps and quantitative trait loci in C. latifolia.

Keywords SSR markers $\cdot 5^{\prime}$ and $3^{\prime}$ anchored ISSR . Genetic variation $\cdot$ Lemba $\cdot$ Polymorphism

\section{Introduction}

Lemba (Curculigo latifolia Dryand) a monocotyledonous perennial herb belongs to the Hypoxidaceae family. The genus Curculigo comprising of about 20 species is distributed in the tropical regions of Asia and Africa [1]. C. latifolia is widely spread in primary and secondary forests throughout Malaysia. Species confounded in Borneo are $C$. racemose and $C$. orchioides. Curculin, which is extracted from fruits of $C$. latifolia has been found to have a sweet taste with sweetness-modifying characteristics of natural sweeteners and has been shown to be a good lowcalorie sweetener [2,3]. It has been proven that curculin is up to 9,000 times sweeter than sucrose [4] and has antidiabetic properties [5]. Therefore, this plant has great potential for the pharmaceutical and food industries. Plants are currently being brought into cultivation. However, prior to cultivation, it is prudent to look at the fundamental knowledge of the population structure of this plant. The beneficial characteristics of the species can be further enhanced through plant breeding, but characterization of 
the available species in Malaysia is loose and considered necessary before any breeding work can commence. Determination of genetic diversity and population structure are prerequisites of breeding programs and a first step in the development and evaluation of plant genotypes.

Microsatellites or simple sequence repeats (SSRs) are tandemly repeated motifs of 1-6 nucleotides found in all prokaryotic and eukaryotic genomes [6]. Since microsatellites are co-dominants inherited, highly abundant, polymorphic, multiallelic, and reproducible with transferability characteristics, they become one of the most desirable markers for use in genetic studies [7]. Interestingly, SSR has been the marker of choice for assessment of genetic variability in many plant species such as commercial peach varieties [8], sugar beet [9], barley [10] and chickpea [11], analysis of phylogenetic relationship [12], marker assisted selection [13], construction of genetic linkage maps [14], and quantitative trait loci (QTL) [15]. Microsatellites may be identified by screening DNA databases, but for this genus no sequence information has been reported and no microsatellite markers were isolated and developed. It was therefore essential to develop microsatellites for $C$. latifolia. The knowledge generated could also be used in related species.

ISSR-PCR is an alternative strategy that has been devised to reduce the time invested in microsatellites isolation and to significantly increase yield [16] without the need for enrichment and/or hybridization screening [17]. Besides, the ISSR-PCR technique targets only those regions of the genome that are rich in microsatellite motifs $[18,19]$. In plants, the construction of microsatellite markers with both $3^{\prime}$ and $5^{\prime}$ anchored ISSR-PCR strategy has been proven to be effective in producing polymorphic loci for different species such as, Canada thistle [20], wheat [21, 22], oil palm [23], Japanese persimmon [24], and turnip [25].

This study was performed with the objectives of to develop polymorphic microsatellite markers for $C$. latifolia using $5^{\prime}$ and $3^{\prime}$ anchored ISSR primers; and to determine the suitability of developed microsatellite markers for genetic variation study using constructing a dendrogram and demonstrating relationships among $C$. latifolia accessions.

\section{Materials and methods}

\section{DNA extraction}

Genomic DNA was extracted from the young leaf of 27 accessions from Peninsular Malaysia using GENE ${ }^{\sqrt{ }}$ ALL $^{\text {TM }}$ Plant SV Mini Kit (from General Biosystem, Seoul, Korea) following manufacturer's instructions with the DNA concentration adjusted to $70 \mathrm{ng} / \mu \mathrm{l}$.
Microsatellite markers development

In this study an accession from Ringlet was used for PCR amplification using ISSR markers. Both $3^{\prime}$ and $5^{\prime}$ anchored ISSR primers were used for microsatellite markers development. The $3^{\prime}$ anchored ISSRs were UBC815 and UBC835 with sequences of $(\mathrm{CT})_{8} \mathrm{G}$ and $(\mathrm{AG})_{8} \mathrm{YC}$, respectively. Three $5^{\prime}$ anchored ISSRs used were RAM1, BP8 and BP10 with sequences of $\mathrm{YHY}(\mathrm{CCA})_{5}$, KKYHYHYHY $(\mathrm{GTT})_{5}$ and $\mathrm{KKDRDRD}(\mathrm{TC})_{10}$ respectively, where $\mathrm{Y}=\mathrm{C} / \mathrm{T}, \mathrm{H}=\mathrm{A} / \mathrm{T} /$ $\mathrm{C}, \mathrm{K}=\mathrm{G} / \mathrm{T}, \mathrm{D}=\mathrm{G} / \mathrm{A} / \mathrm{T}$ and $\mathrm{R}=\mathrm{A} / \mathrm{G}$.

PCR was carried out in a total volume of $25 \mu$ including deionized water, $1 \times$ PCR buffer plus $\mathrm{MgSO}_{4}, 200 \mu \mathrm{M}$ dNTP mix, $0.6 \mu \mathrm{M}$ primer, 0.75 Pfu DNA polymerase and $70 \mathrm{ng} / \mu \mathrm{l}$ DNA. The thermal cycler with the touchdown thermal cycling protocol starting with three minutes of denaturing at $94^{\circ} \mathrm{C}$ was followed by the remaining thermal cycling protocol where temperature was set to $94^{\circ} \mathrm{C}$ for $40 \mathrm{~s}$. The annealing step was started at $10^{\circ} \mathrm{C}$ above optimum annealing temperature for $30 \mathrm{~s}$ and then reduced by $1^{\circ} \mathrm{C}$ per cycle until optimum annealing temperature followed by $60 \mathrm{~s}$ extension time at $72^{\circ} \mathrm{C}$. The program was followed by the remaining thermal cycling protocol where temperature was set to $95^{\circ} \mathrm{C}$ for $40 \mathrm{~s}$, then at the primer's optimum annealing temperature for $50 \mathrm{~s}$, and extension at $72^{\circ} \mathrm{C}$ for $60 \mathrm{~s}$, for a total of 30 cycles with a final ten minutes extension at $72^{\circ} \mathrm{C}$. Amplified products were resolved via $2 \%$ agarose gel, stained by ethidium bromide and visualized by UV-light.

Fragments ranging from 250 to 1,300 were purified using Gene $\mathrm{JET}^{\mathrm{TM}}$ PCR Purification Kit (Fermentas) and ligated into pCR ${ }^{\circledR}$ II-Blunt-TOPO ${ }^{\circledR}$ vector $\left(\right.$ Zero Blunt ${ }^{\circledR}$ TOPO $^{\circledR}$ PCR Cloning Kit, Invitrogen ${ }^{\circledR}$ ) following manufacturer's instructions and then transformed into Escherichia coli DH5 $\alpha$ component cells. Transformed clones were grown overnight in selective media (LB-Amp). Ten randomly selected recombinant clones were grown overnight in LB broth and plasmids DNA were extracted using PureLink ${ }^{\mathrm{TM}}$ Quick Plasmid Miniprep Kit $\left(\right.$ Invitrogen $\left.^{\circledR}\right)$. Extracted plasmid DNA of recombinant clones was sequenced. Microsatellite motifs were screened using Microsatellite Repeat Finder-Online Bioinformatic Tools and primers were designed using PRIMER3 Version 0.4.0 (http://frodo.wi.mit.edu/primer3/). The major parameters for primer design were set as follows: primer length from 20 to 25 nucleotides, PCR products size from 140 to $310 \mathrm{bp}$, annealing temperatures at $55.5-61.5^{\circ} \mathrm{C}$ and $\mathrm{GC}$ content of between 40 and $60 \%$.

Microsatellites genotyping

The developed primers were tested on 27 accessions of $C$. latifolia, 16 of which were collected from Jelebu, Negeri Sembilan (accession 13-27) and the rest from all other 
Fig. 1 DIVA-GIS mapping of collection sites of $C$. latifolia from Peninsular Malaysia

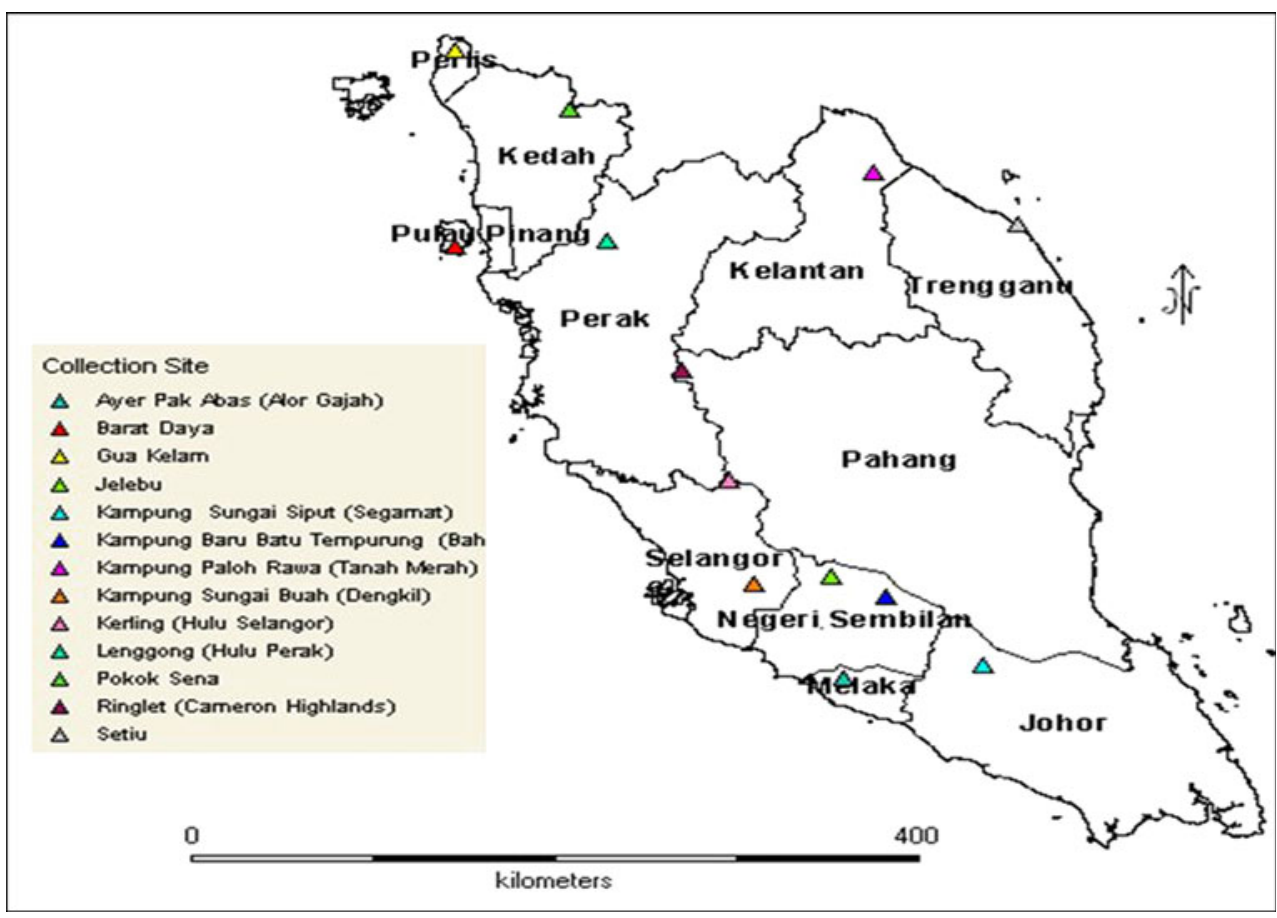

states in Peninsular Malaysia. The locations of $C$. latifolia accessions used for genetic variability study are illustrated using DIVA-GIS software version 7.2.1 (Fig. 1). PCR amplifications were performed in $25 \mu$ l volumes containing 0.75 U Pfu DNA polymerase (Fermentas), $1 \times$ PCR buffer plus $\mathrm{MgSO}_{4}, 200 \mu \mathrm{M}$ dNTP mix, $0.4 \mu \mathrm{M}$ of each primer set, and $70 \mathrm{ng}$ template DNA. The PCR program used was as mention previously. Amplification products were resolved via $4 \%$ methaphor agarose gel using ethidium bromide staining. A 50-bp DNA ladder (Fermentas) was used as a reference marker to determine the size of alleles.

\section{Data analysis}

The observed $\left(\mathrm{N}_{\mathrm{a}}\right)$ and effective $\left(\mathrm{N}_{\mathrm{e}}\right)$ number of alleles, observed $\left(\mathrm{H}_{\mathrm{o}}\right)$ and expected $\left(\mathrm{H}_{\mathrm{E}}\right)$ heterozygosity, Shannon's information index (I) and Hardy-Weinberg equilibrium (HWE) were calculated with the software POPGENE Version 1.31 [26]. Polymorphism information content (PIC), a measure of allelic diversity at a locus was calculated using the following formula.

PIC $=1-\sum_{i=1}^{n} p_{i}^{2}-\sum_{i}^{n-1} \sum_{j=i+1}^{n} 2 p_{i}^{2} p_{j}^{2}$

where $p_{i}$ is the frequency of the $i$ th allele, and $n$ is the number of alleles [27].

The binary data attained from scoring of microsatellite markers were analyzed using NTSYS-pc 2.1 in order to reveal the genetic variability and associations among C. latifolia accessions. The coefficients of genetic similarity were computed using Dice's similarity coefficient. This similarity matrix was used to create a dendrogram using the unweighted paired group method using arithmetic average (UPGMA). Principal component analysis (PCA) was also carried out to explore associations among accessions [28].

Gap statistics was computed to estimate the number of clusters in the dendrogram [29]. The gap statistics were analyzed using $\mathrm{R}$ software version 2.15.0 using matrix data.

\section{Results}

Sequence analysis of cloned fragments

Among the 68 randomly-selected clones of inserted fragments amplified from the five ISSR markers, a total of 50 clones were selected for sequence analyses. The average size of the inserts obtained from the sequencing was $532 \mathrm{bp}$. All 50 recombinant clones which were sequenced contained microsatellite motifs at both ends and the presence of additional internal microsatellites observed in some clones implied clustering of microsatellites in several genomic regions. Among these, 36 clones $(72 \%)$ had unique sequences that were different from each other. The remaining 14 clones displayed the same sequences present in the selected unique clones. Since fragments with different sizes were selected for sequencing, this resulted in the isolation of mostly $(72 \%)$ unique microsatellite loci and a few redundant sequences. Nucleotide sequence data with the microsatellite loci are available in the GenBank databases under the accessions number reported in Table 1 . 


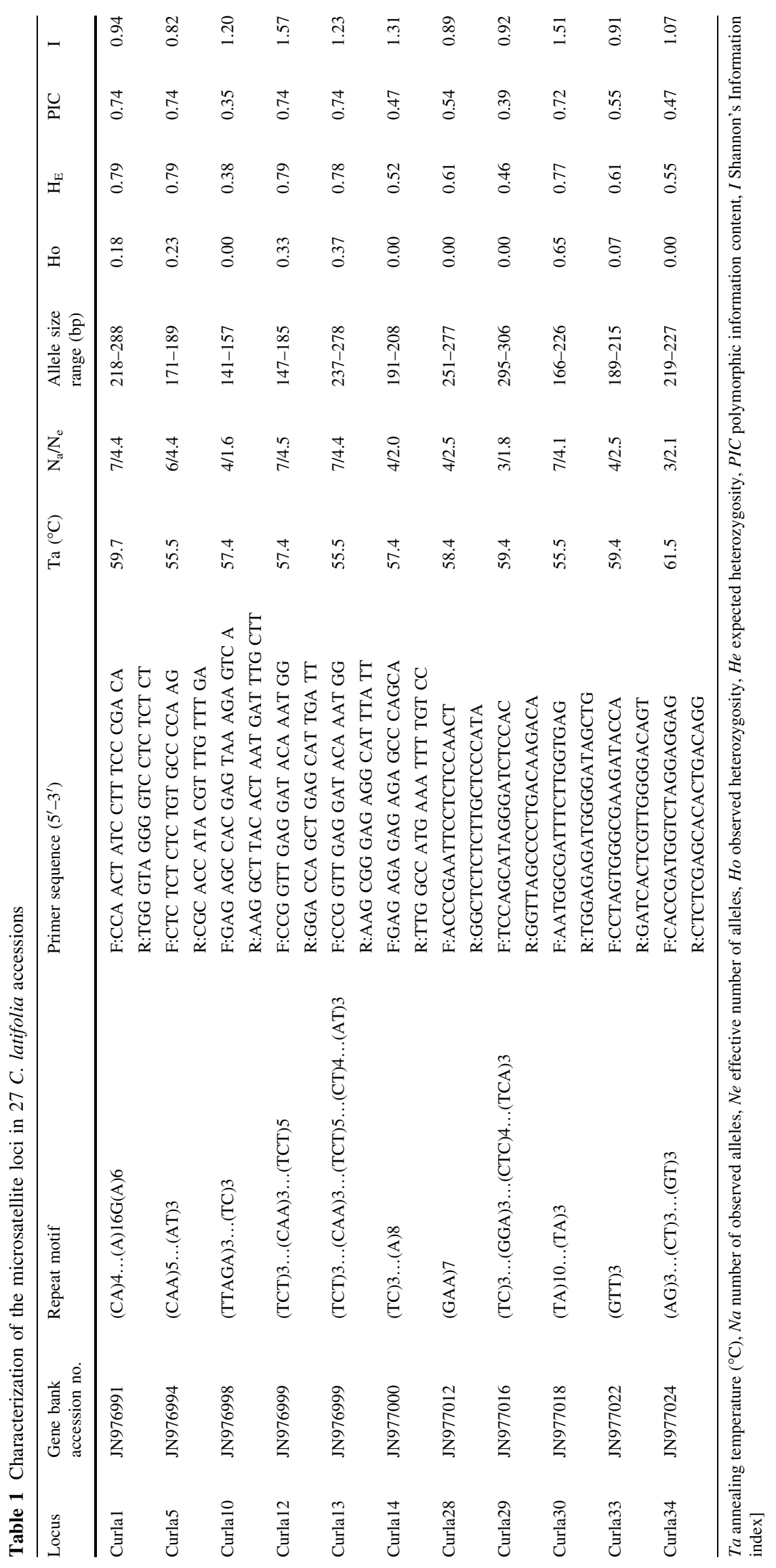


With the use of ISSR primers for selective amplification of microsatellite-rich DNA fragments, all clones contained reverse complementary repeated motifs at the two ends. The clones containing CT, AG, CCA, GTT and TC motifs at the $5^{\prime}$ ends carried GA, TC, GGT, CAA and AG motifs respectively, at the $3^{\prime}$ ends.

A total of 235 microsatellite regions were identified from the sequencing results consisting of different microsatellite core units. Among all microsatellite motifs found, the dinucleotide core was the most frequent with 121 motifs, followed by mononucleotides and trinucleotides with 64 and 47 motifs, respectively. In contrast, only two and one tetranucleotide and pentanucleotide motifs respectively were found, and no hexanucleotide microsatellite motif was found among all sequences. Among the selected sequenced clones, $86.1 \%$ (31 out of 36 unique sequences) contained internally located microsatellite motifs in addition to those at the ends with variable flanking regions on both sides of the motifs. Based on Weber's (1990) classification rules [30], among the 36 unique sequences, 99 perfect microsatellites without interruption, five compound repeat sequences with adjacent tandem microsatellites of a different sequence, and 10 imperfect/interrupted compound microsatellites with one or more interruptions in the run of repeats were found centrally located at the sequences.

\section{Microsatellite polymorphism within C. latifolia accessions}

Of the total 34 designed primer pairs on the flanking regions of both perfect and interrupted compound microsatellites, 22 loci successfully amplified $C$. latifolia genomic DNA and out of these 22 primer pairs, 11 primer sets were polymorphic (Table 1). A total of 56 alleles were found at these 11 polymorphic loci and the total effective number of alleles was 34.3. The number of observed alleles (Na) per locus ranged from three (Curla29 and Curla34) to seven (Curla1, Curla12, Curla13, and Curla30) with an average of 5.1. The effective number of alleles ranged from 1.6 (Curla10) to 4.5 (Curla12) with an average of 3.12. The allele size was between 141 and 306 bp which conformed to the expected allele size parameter for microsatellite markers development. The genetic profiles of some accessions are illustrated in Fig. 2. The observed heterozygosity ranged from 0.00 (Curla10, Curla14, Curla28, Curla29, and Curla34) to 0.65 (Curla30), whereas the expected heterozygosity ranged from 0.38 (Curla10) to 0.79 (Curla1, Curla5, and Curla12). The polymorphic information content (PIC) value was between 0.35 (Curla10) and 0.74 (Curla1, Curla5, Curla12, and Curla13), with an average of 0.59 . Thus, four of the loci (Curla10, Curla14, Curla29, and Curla34) were moderately polymorphic $(0.25<\mathrm{PIC}<0.5)$ and the eight remaining loci were highly polymorphic $(0.5<$ PIC), while none of the loci showed low polymorphism. The mean Shannon's Information index (I) was 1.13, and ranged from 0.82 (Curla5) to 1.57 (Curla12). All loci deviated significantly from Hardy-Weinberg equilibrium.

Genotyping and variability analysis

The allelic data obtained with the 11 primer pairs across 27 accessions was scored and computed to obtain the Dice's similarity coefficient. The relationships among these accessions using Dice's similarity coefficients are indicated in Additional file 1. The average value of Dice's similarity coefficient calculated was 0.44 . The highest similarity coefficient, 0.81, was between accessions 7 and 8 from Pokok Sena and Gua Kelam and the lowest, 0.00, was between accessions 1 and 5 from Kerling and Lenggong respectively. Based on Dice's similarity coefficient, a dendrogram was generated using UPGMA cluster analysis (Fig. 3). The similarity matrix also was used to estimate number of clusters using gap statistics analysis. It was found from results that a gap was observed between $\mathrm{K}=1$ and $\mathrm{K}=2$ (Table 2). This indicated that the dendrogram clearly distinguishes accessions surveyed into two clusters based on the calculated gap statistics (Fig. 4). The accession from Kerling, presented the lowest similarity values compared to those from the main group and it was placed as a cluster individually. The dendrogram revealed that accessions from neighboring states or geographically close locations almost grouped together indicating their genetic similarity. All accessions from Jelebu except accession 16 clustered into one sub-group on the similarity coefficient of 0.47. This indicated that accessions collected from one location was almost similar than accessions taken from different states.
Fig. 2 The genetic profiles of 12 accessions of $C$. latifolia using a primer Curla13 and b Curla 33 (M: 50 bp DNA ladder (fermentas); 1-12: Accessions of $C$. latifolia)
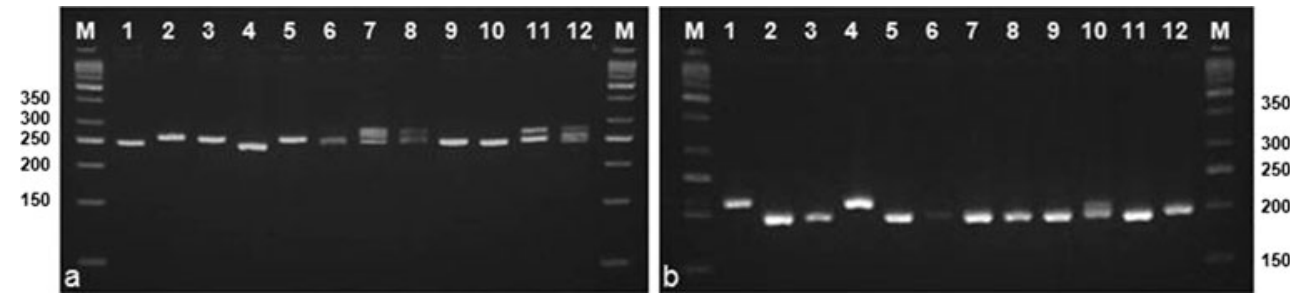


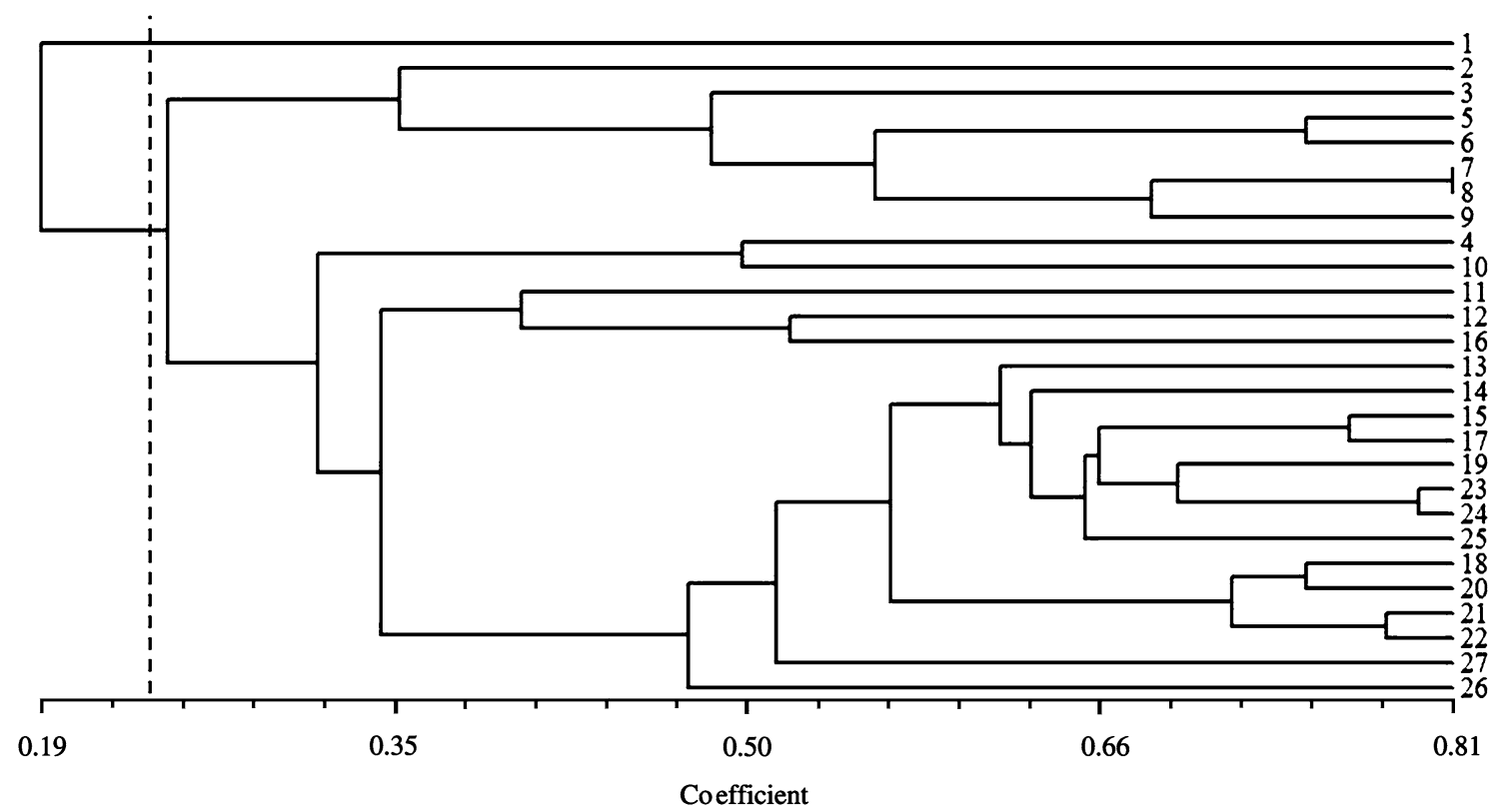

Fig. 3 Dendrogram based on Dice's similarity coefficient indicating relationships among accessions of $C$. latifolia

Table 2 Gaps calculated for estimating number of clusters in the dendrogram

\begin{tabular}{lllllllllll}
\hline K & 1 & 2 & 3 & 4 & 5 & 6 & 7 & 8 & 9 & 10 \\
\hline Gap & 0.403 & 1.003 & 1.119 & 1.151 & 1.171 & 1.191 & 1.218 & 1.257 & 1.294 & 1.327 \\
\hline
\end{tabular}

$K$ number of cluster

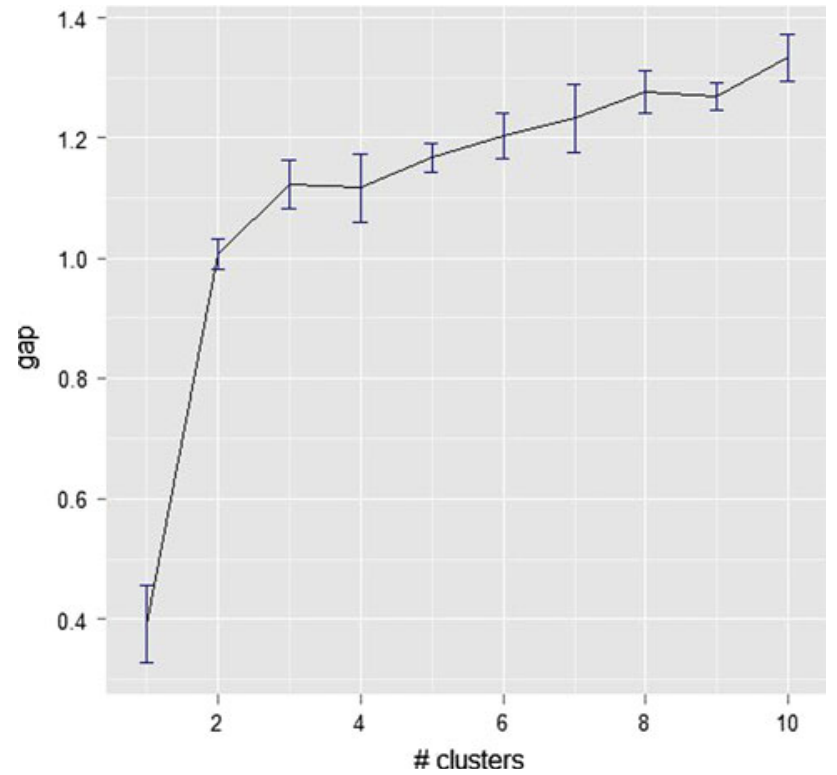

Fig. 4 The gap curve indicated number of clusters revealed

The binary data generated from the 27 C. latifolia accessions were also subjected to principal component analysis (PCA) to visualize accessions in a multivariate space. The first two principal components (PCs) extracted a cumulative of $53.80 \%$ of the variance in the C. latifolia accessions. The first two components contributed 40.80 and $13.00 \%$ of the total variation, respectively. The distribution of the accessions in the two-dimensional graph derived based on the first two principle components shows precisely the genetic status and association of accessions (Fig. 5). Results from both clustering and principle component analysis grouped $C$. latifolia accessions from Jelebu into one group which corresponded well to the close location (Fig. 3).

\section{Discussion}

As indicated earlier the genus Curculigo, although widely distributed in Malaysia, Indonesia and Brunei, has not been characterized for genomic sequences and microsatellite development. Therefore, these developed microsatellite markers for $C$. latifolia could facilitate future population genetic studies and breeding programs for this plant and related species.

Microsatellite markers are characterized by a high degree of variability making them powerful tools for population genetic analyses [11]. The conventional protocols used for the isolation of microsatellites are cost, time 
Fig. 5 Two-dimensional plot of principle components of SSR marker data among $C$. latifolia accessions (Dim-1, Dim-2: the two axes represent the first two principle components; labels in the graph show the collection site of C. latifolia)

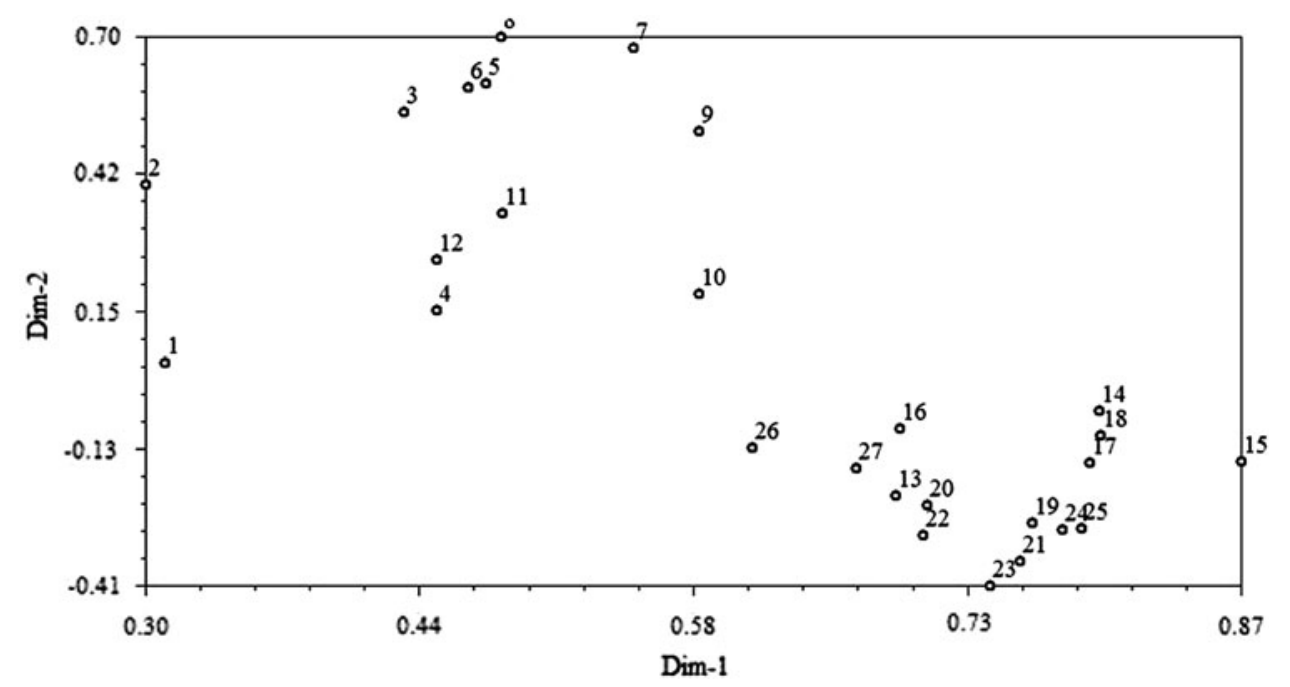

and labor intensive and the efficiency of microsatellite isolation is low [16]. The primer extension strategy has been proven to be useful for the isolation of dinucleotide repeat microsatellites. Although enrichment method is more desirable than traditional, it is still time consuming because of many several steps and needs more investigation to gain tri- or tetra nucleotide containing microsatellites [31]. The isolation of microsatellites from plants is technically more demanding as their frequency in plants is relatively low comparing to animal genomes [32]. To overcome these limitations ISSR-PCR technique as targets only those regions of the genome those are rich in microsatellite motifs is a desirable strategy. This technique was highly successful, as over $86 \%$ of unique clones obtained, contained internally located microsatellite motifs in addition to those at the ends.

In this study using ISSR-PCR technique, 11 polymorphic microsatellites have been developed and screened in 27 accessions of $C$. latifola. All the variability parameters calculated for the microsatellites described in the study indicated that microsatellites will become a useful tool for genetic variation studies, genotype identification and similarity analysis in C. latifolia. The average of 5.1 observed alleles and 3.12 of effective alleles per locus was detected in this study. The difference between average number of observed alleles and effective number of alleles was due to the uneven frequency of each allele [33]. PIC provides an estimate of discriminatory power of a marker to differentiate genotypes based on both the number of alleles expressed and their relative frequencies [34]. The average of PIC value was 0.59 which indicate an isolation of highly polymorphic microsatellites. This was consistent with findings on potential applications of ISSR-PCR technique in developing high polymorphic microsatellites in Sphagnum capillifolium with low level of genetic variation [17]. Overall genetic variability for the accessions studied, represented by Shannon's indexes, was particularly high with the average of 1.13 . The high value of Shannon's information index represents the effectiveness of microsatellite loci to reveal the variation. The results indicated that all loci deviated significantly from HWE. Possible explanations for deviations of loci from HWE are heterozygote deficiency in loci [33], population size, and propagation through rhizomes.

The values obtained with Dice's coefficient indicated that the extent of genetic variability among accessions varies, but that in most cases, genetic similarity is higher among accessions from one location or neighboring states. The highest Dice's similarity coefficient (0.81) was found between accessions 7 and 8 , indicating that they had almost the same genetic constituents based on the 11 microsatellite primers used. The lowest similarity coefficient (0.00) was found between accessions 1 and 5 which indicates that they were relatively remote in relationship.

The high level of genetic polymorphism was clearly evident from the dendrogram. C. latifolia is reported to be a cross-pollinating species [1]. The relatively high level of polymorphism could be due to cross pollination in this species, however low level of variation among accessions from confined population of a small size could be referred to propagation through rhizome in the species. The low genetic diversity among accessions of $C$. latifolia taken from one location also reported as a result of vegetative propagation through rhizome [35]. The rhizome propagation theoretically has a similar effect in population genetic structure as strict selfing [36].

The two-dimensional graph of accessions differentiation was revealed by PCA. This type of graphical illustration enables the assessment of the population structure and geometric distances among all of the accessions in the study [37]. The distribution of the accessions in the two-dimensional graph based on the first two principle 
components was similar to that obtained from cluster analysis, where all accessions collected from one location in Jelebu were distinctly separated from other accessions.

\section{Conclusion}

In conclusion, 11 polymorphic microsatellite markers in C. latifolia were developed by the $5^{\prime}$ and $3^{\prime}$ anchored PCR technique. All the loci showed considerable variation in the population of this plant collected from within Malaysia. These results indicated that microsatellite primers tested could clearly distinguish the different sets of genotypes. The characteristics of these loci provide useful information for further studies on population genetics, assessment of genetic stability and somaclonal variation, construction of genetic linkage maps and mapping of economically quantitative trait loci, estimation of genetic diversity and divergence in $C$. latifolia and related plants. The use of these microsatellite markers will also facilitate the management and exploration of genetic resources of Hypoxidaceae in the lower Asparagales and assist in their genetic improvement to some extent.

Acknowledgments The authors would like to acknowledge the Ministry of Agriculture, Malaysia for funding this project under the e-Science Fund (05-01-04-SF1051).

Open Access This article is distributed under the terms of the Creative Commons Attribution License which permits any use, distribution, and reproduction in any medium, provided the original author(s) and the source are credited.

\section{References}

1. Kocyan A (2007) The discovery of polyandry in Curculigo (Hypoxidaceae): implications for androecium evolution of asparagoid monocotyledons. Ann Bot 100:241-248

2. Koizumi A, Nakajima K, Asakura T, Morita Y, Ito K, ShmizuIbuka A, Misaka T, Abe K (2007) Taste-modifying sweet protein, neoculin, is received at human T1R3 amino terminal domain. Biochem Biophys Res Commun 358:585-589

3. Yamashita H, Theerasilp S, Aiuchi T, Nakaya K, Nakamura Y, Kurihara Y (1990) Purification and complete amino acid sequence of a new type of sweet protein taste-modifying activity, curculin. J Biol Chem 265:15770-15775

4. Kurihara Y, Nirasawa S (1994) Sweet, antisweet and sweetnessinducing substances. Trends Food Sci Tech 5:37-42

5. Kant R (2005) Sweet proteins-Potential replacement for artificial low calorie sweeteners. Nutr J 4(5):1-6

6. Goldstein DB, Pollock DD (1997) Launching microsatellites: a review of mutation processes and methods of phylogenetic inference. J Hered 88:335-342

7. Zheng Y, Zhang G, Lin F, Wang Z, Jin G, Yang L, Wang Y, Chen X, Xu Z, Zhao X (2008) Development of microsatellite markers and construction of genetic map in rice blast pathogen Magnaporthe grisea. Fungal Genet Biol 45:1340-1347

8. Maria A, El-Kadri A, Werner H, Pere A (2010) Genetic variation, population structure and linkage disequilibrium in peach commercial varieties. BMC Genet 11:69

9. Marinus S, Esselink G, Isabelle E, De Riek Jan VB (2010) Characterisation of sugar beet (Beta vulgaris L. ssp. vulgaris) varieties using microsatellite markers. BMC Genetics 11:41

10. Lyudmyla MO, Martin G, Marion R (2006) Analysis of molecular diversity, population structure and linkage disequilibrium in a worldwide survey of cultivated barley germplasm (Hordeum vulgare L.). BMC Genetics 7:6

11. Sethy NK, Shokeen B, Edwards KJ, Bhatia S (2006) Development of microsatellite markers and analysis of intraspecific genetic variability in chickpea (Cicer arietinum L.). Theor Appl Genet 112:1416-1428

12. Biswas MK, Chai L, Mayer C, Xu Q, Guo W, Deng X (2011) Exploiting BAC-end sequences for the mining, characterization and utility of new short sequences repeat (SSR) markers in Citrus. Molecular Biol Rep 1-14

13. Ashkani S, Rafii MY, Rusli I, Sariah M, Abdullah SNA, Abdul Rahim H, Latif M (2012) SSRs for marker-assisted selection for blast resistance in rice (Oryza sativa L.). Plant Mol Biol Rep 30:79-86

14. Hong Y, Chen X, Liang X, Liu H, Zhou G, Li S, Wen S, Holbrook CC, Guo B (2010) A SSR-based composite genetic linkage map for the cultivated peanut (Arachis hypogaea L.) genome. BMC Plant Biol 10:17

15. Zhang M, Zhang R, Yang J, Luo P (2010) Identification of a new QTL for Fusarium head blight resistance in the wheat genotype "Wang shui-bai". Mol Biol Rep 37:1031-1035

16. Zane L, Bargelloni L, Patarnello T (2002) Strategies for microsatellite isolation: a review. Mol Ecol 11:1-16

17. Provan J, Wilson PJ (2007) Development of microsatellites for the peat moss Sphagnum capillifolium using ISSR cloning. Mol Ecol Notes 7:254-256

18. Nest M, Steenkamp E, Wingfield B, Wingfield M (2000) Development of simple sequence repeat (SSR) markers in Eucalyptus from amplified inter simple sequence repeats (ISSR). Plant Breed 119:433-436

19. Zietkiewicz E, Rafalski A, Labuda D (1994) Genome fingerprinting by simple sequence repeat (SSR)-anchored polymerase chain reaction amplification. Genomics 20:176-183

20. Slotta TA, Foley ME, Horvath D (2005) Development of polymorphic markers for Cirsium arvense, Canada thistle, and their amplification in closely related taxa. Mol Ecol Notes 5:917-919

21. Hayden MJ, Sharp P (2001) Targeted development of informative microsatellite (SSR) markers. Nucleic Acids Res 29:e44

22. Song Q, Fickus E, Cregan P (2002) Characterization of trinucleotide SSR motifs in wheat. Theor Appl Genet 104:286-293

23. Singh R, Nagappan J, Tan SG, Panandam JM, Cheah SC (2007) Development of simple sequence repeat (SSR) markers for oil palm and their application in genetic mapping and fingerprinting of tissue culture clones. Asia Pac J Mole Biol Biotechnol 15:121-131

24. Guo D, Luo Z (2006) Development of SSR primers using ISSRPCR in Diospyros kaki Thunb. Mol Ecol Notes 6:621-622

25. Cui X, Dong Y, Hou X, Cheng Y, Zhang J, Jin M (2008) Development and characterization of microsatellite markers in Brassica rapa ssp. chinensis and transferability among related species. Agric Sci China 7:19-31

26. Yeh F, Yang R, Boyle T (1999) Microsoft window-based freeware for population genetic analysis (POPGENE version 1.31). University of Alberta and Centre for International Forestry Research 
27. Botstein D, White RL, Skolnick M, Davis RW (1980) Construction of a genetic linkage map in man using restriction fragment length polymorphisms. Am J Hum Genet 32:314-331

28. Rohlf F (2002) NTSYS-pc: numerical taxonomy system, version 2.1. Exeter Publishing. Ltd., Setauket, New York

29. Tibshirani R, Walther G, Hastie T (2001) Estimating the number of clusters in a data set via the gap statistic. J R Stat Soc B (Stat Methodol) 63:411-423

30. Weber JL (1990) Informativeness of human (dC-dA)n·(dG-dT)n polymorphisms. Genomics 7:524-530

31. Paetkau D (1999) Microsatellites obtained using strand extension: an enrichment protocol. Biotechniques 26:690-694

32. Maguire TL, Edwards KJ, Saenger P, Henry R (2000) Characterisation and analysis of microsatellite loci in a mangrove species, Avicennia marina (Forsk.) Vierh. (Avicenniaceae). Theor Appl Genet 101:279-285

33. Liao M, Wang Y, Rong X, Zhang Z, Li B, Wang L, Chen G (2011) Development of new microsatellite DNA markers from
Apostichopus japonicus and their cross-species application in Parastichopus parvimensis and Pathallus mollis. Int J Mol Sci 12:5862-5870

34. Nagl N, Taski-Ajdukovic K, Popovic A, Curcic A, Danojevic D, Kovacev L (2011) Estimation of genetic variation among related sugar beet genotypes by using RAPD. Genetika 43:575-582

35. Ranjbarfard A (2011) Genetic diversity of Curculigo latifolia based on morphological characteristics and ISSR markers. Universiti Putra Malaysia, Malaysia

36. Song Z, Guan Y, Rong J, Xu X, Lu BR (2006) Inter-simple sequence repeat (ISSR) variation in populations of the cutgrass Leersia hexandra. Aquatic botany 84:359-362

37. De Sousa ACB, Jank L, De Campos T, Sforca DA, Zucchi MI, De Souza AP (2011) Molecular diversity and genetic structure of guineagrass (Panicum maximum Jacq.), a tropical pasture grass. Trop Plant Biol 4:185-202 